\title{
Insecticide-treated net ownership, utilization and knowledge of malaria in children residing in Batoke-Limbe, Mount Cameroon area: effect on malariometric and haematological indices
}

Rene Ning Teh ${ }^{1,2^{*}}$, Irene Ule Ngole Sumbele ${ }^{1,6}$, Derick Ndelle Meduke ${ }^{1}$, Gillian Asoba Nkeudem ${ }^{1,2}$, Samuel Takang Ojong ${ }^{1,3}$, Exodus Akwa Teh ${ }^{4}$ and Helen Kuokuo Kimbi ${ }^{1,5}$

\begin{abstract}
Background: Insecticide-treated nets (ITNs) are the most widely used interventions for malaria control in Africa. The aim of this study was to assess the ownership and utilization of ITNs and the knowledge of malaria and their effects on malariometric and haematological indices in children living in the Mount Cameroon area.

Methods: A community-based cross-sectional study involving a total of 405 children aged between 6 months and 14 years living in Batoke-Limbe was carried out between July and October 2017. A semi-structured questionnaire was used to document demographic status, knowledge on malaria and ITN ownership and usage. Venous blood sample was collected from each child to determine the prevalence and intensity of parasitaemia by Giemsa-stained microscopy and full blood count by auto haematology analysis to obtain white blood cell (WBC) and red blood cell (RBC) counts, haemoglobin $(\mathrm{Hb})$ level, haematocrit (Hct), mean corpuscular volume (MCV), mean corpuscular haemoglobin $(\mathrm{MCH})$ and mean corpuscular haemoglobin concentration (MCHC). A multilinear regression model was used to determine the relationship between haematological parameter as dependent variable and the independent variables.

Results: The overall prevalence of parasitaemia, anaemia, knowledge about malaria, ITN ownership, usage and effective usage was $46.7 \%, 54.7 \%, 40.7 \%, 78.8 \%, 50.9 \%$ and $29.9 \%$, respectively. The prevalence of parasitaemia was significantly higher $(P<0.001)$ in children who ineffectively utilized ITNs $(54.9 \%)$ than effective users $(27.3 \%)$. Having knowledge of malaria, negatively correlated with WBC counts $(P=0.005)$, but positively correlated with $\mathrm{Hb}$ levels $(P<0.001)$, RBC counts $(P<0.001)$, Hct $(P<0.001), M C V(P<0.001)$ and $M C H(P<0.001)$. ITN use positively correlated with WBC counts $(P=0.005)$ but negatively with Hb levels $(P=0.004)$, RBC counts $(P=0.006)$, and $M C H(P<0.001)$. Meanwhile, parasitaemia negatively correlated with Hb levels $(P=0.004)$, RBC counts $(P=0.01)$, Hct $(P=0.04)$ and $M C H C(P=0.015)$.
\end{abstract}

Conclusion: There is need for more sensitization on the benefits of using the ITNs to meet up with the intended and expected impact of the free distribution of ITNs.

Keywords: Malaria, ITN, Ownership, Utilization, Anaemia, Knowledge, Children

*Correspondence: teh.rene@ubuea.cm

${ }^{1}$ Department of Zoology and Animal Physiology, University of Buea, Buea, Cameroon

Full list of author information is available at the end of the article

\section{Background}

Globally, malaria is still a public health concern as 228 million cases of malaria occurred worldwide in 2018 compared with 251 million cases in 2010 and 231 
million cases in 2017, with Cameroon accounting for $3 \%$ of the total number [1]. Also, an estimated 445,000 deaths was caused by malaria in 2016 and Cameroon alone accounted for $3 \%$ of this number [2], despite the control measures put in place [3-5]. Insecticide-treated nets (ITNs) are effective tools for malaria prevention and have been shown to significantly reduce malaria episodes, severe disease, and malaria-related deaths especially among children aged less than five years in endemic areas [6]. At high coverage levels, ITNs provide both individual and community protection for both users and non-users by killing the Anopheles vector, thereby considerably reducing their longevity and entomological inoculation rate [7]. Lengeler [8] reported that ITNs had helped to reduce malaria episodes by $48-50 \%$ and in addition, Bhatt et al. [9], reported that between 2001 and 2015, malaria parasite prevalence in endemic countries reduced by $50 \%$, with $68 \%$ of this decline attributed to the use of ITNs. Conversely, some studies have reported an increase in malaria parasites after increasing the coverage of ITN [10-12].

In 2018, the World Health Organization (WHO) [1], reported that $50 \%$ of the people at risk of malaria in subSaharan Africa slept under an ITN, with half of the population being protected by this intervention, an increase from $29 \%$ in 2010. In order to achieve the Abuja target of $80 \%$ usage and reduce malaria burden in Cameroon, so far, progress has been made in the distribution of longlasting insecticidal nets (LLINs), particularly through campaigns for more than 8 million to 12 million LLINs were distributed between 2011 and 2016 [13]. Yet, proportions $(18.2 \%)$ of these nets are used for other purposes, such as fishing, nursing seeds and football nets [6]. In some cases, they are not used at all for varied reasons such as heat, the feeling of being in a coffin, dislike of colour or pregnant woman keeping it to use for the new-born. So, ownership does not necessarily translate to utilization. Therefore, this could undermine the aim of the 2016 net distribution campaign. Studies carried out in the Mount Cameroon area reported a higher proportion of households with at least one ITN (77.6\%), with a low bed space coverage of $58.5 \%$ [14], indicating that coverage defined by the WHO as one ITN for every two persons remains a challenge. Furthermore, several intervention studies have been carried out on malaria and some enhanced control measures $[4,5,15]$ in the Mount Cameroon area, and the findings revealed ITN efficacy in reducing malaria parasite infection, although such drop may not be homogenous across the country. However, there are also concerns on the increasing pyrethroid resistance, which is likely to affect LLIN efficacy in preventing malaria parasite infection. Even though a study in Cameroon [16] as well as various studies in Malawi
[17], Benin [18, 19] and several countries in Africa [20] reported that LLINs still offers some protection even in areas of high pyrethroid resistance, there is need for continuous surveillance and evaluation on the effective use of LLINs distributed by the Cameroon government and its partners to reduce malaria mortality and morbidity.

Irrespective of the increased ownership of ITNs/LLINs, a decrease in malaria transmission or morbidity is still to be appreciated especially as Cameroon is reported to harbour the five most efficient and common malaria vectors (Anopheles gambiae, Anopheles arabiensis, Anopheles funestus, Anopheles nili and Anopheles moucheti) [21]. Moreover, the effective control of malaria within a community is affected by their cultural beliefs $[22,23]$. In addition, Tyagi et al. [23] reported that community knowledge about malaria causation, symptoms, treatment and prevention has been linked to the inability of malaria programs to achieve sustainable control. It is thus imperative to evaluate the influence of the ownership and utilization of treated mosquito bed nets, malaria knowledge and it influence on the malariometric and haematological indices in children living in a malaria endemic zone, such as Batoke-Limbe, in the Mount Cameroon area.

\section{Methods \\ Study area and participants}

The study was conducted in Batoke-Limbe a coastal community in the Fako Division of the South West Region of Cameroon. The area is subjected to a Cameroonian-type equatorial climate characterized by fairly constant temperatures and two seasons. Batoke-Limbe is situated at the foot of Mount Cameroon and is bounded to the west by the Atlantic Ocean. The area has been described in detailed by Teh et al. [24].

Fishing, oil palm plantation agriculture and small-scale peasant farming are the main agricultural practices in this community. The main house type is mostly plank, although block houses are also common. Some of the plank houses are quite old with many crevices on the walls and many others have no ceiling or a window mosquito mesh as seen in Fig. 1.

All children $\leq 14$ years in Batoke-Limbe whose parents/caregivers signed the consent/assent forms and had resided in the area for at least a month, were recruited in the study. Children who presented with high fever or any other medical conditions requiring intensive care hospitalization, were excluded from the study.

\section{Study design}

The community-based cross-sectional study was conducted between the months of July to October 2017, during the peak malaria transmission period in the Mount 

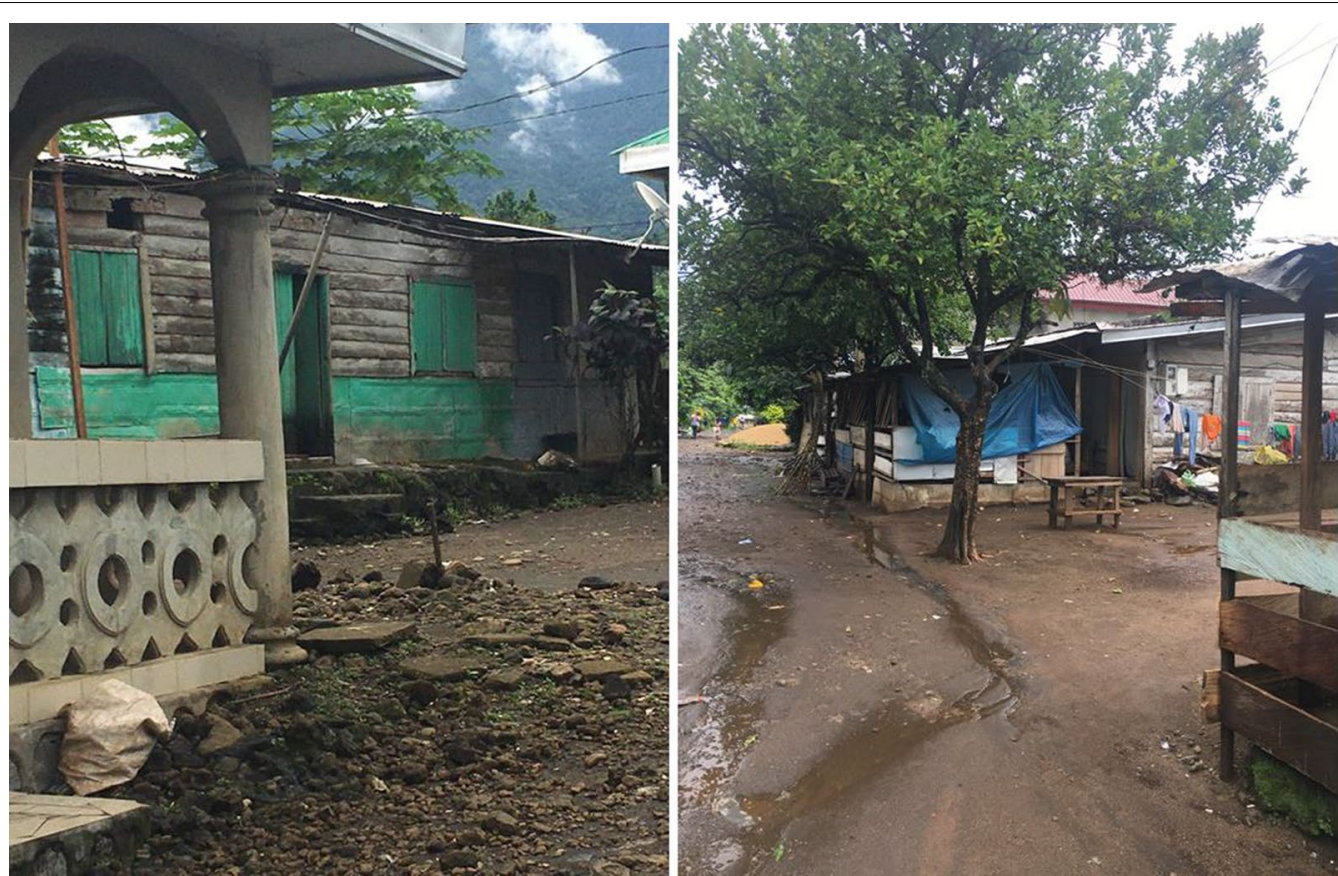

Fig. 1 Plank houses with crevices on the walls

Cameroon area [25]. Participants were invited to the data collection location in each community by their local chiefs and coordination was organised by the head/leader of a block within a neighbourhood (quarter head) of the various communities. Following prior sensitization of the community, a date for collection of samples was made for each family to ensure the participation of at least a child less than or equal to 14 years in the study.

\section{Sample size and population}

The sample size was calculated using the following formula [26]:

$$
\mathrm{n}=\mathrm{Z}^{2} \mathrm{pq} / \mathrm{d}^{2}
$$

where $\mathrm{z}=1.96$ : confidence level test statistics at the desired level of significance, $\mathrm{q}=1-\mathrm{p}$ : proportion of malaria parasite negative and $\mathrm{d}=$ acceptable error willing to be committed, $\mathrm{P}=29.6 \%$, prevalence of malaria in children $\leq 14$ years in the study area [15]. The minimum estimated sample size calculated was approximately 325 . After adding 15\% non-response rate, the sample size obtained was 382 . The required sample size was attained after a convenient sampling method was used in all the blocks. The final sample size was adjusted to a minimum of 400 participants to account for anticipated incomplete data entry and blood loss by clotting. The study participants included pairs of children between 6 months and 14 years and their parents or caregiver.

\section{Data collection}

Semi-structured questionnaires, with questions on ITN usage and its state, derived from Sumbele et al. [4] were administered to the parents/guardians/caregivers. Pidgin, English or French languages were used to administer the questionnaire depending on the language of choice requested by the respondent. ITN use was defined as having slept under an ITN the night prior to the survey. Children, who had good nets, used them regularly and slept before $10 \mathrm{pm}$, were considered as effective users. All reported ITNs were inspected except in some cases where inspection was not possible (locked room). The physical integrity of each ITN was assessed by checking for holes in the nets and counting them using the WHO Pesticide Evaluation Scheme (WHOPES), which defined sizes as recommended by the WHO [27].

Relating to the knowledge and scoring of malaria; the questions relevant to knowledge of malaria in the questionnaire were derived from Kimbi et al. [28]. For analysis, a total of 13 items were included in the knowledge section which included signs and symptoms, effects, transmission and control measures. The combined level of knowledge was classified according to each respondent's score. Appropriate knowledge corresponded to a 
score greater than the mean score while inappropriate knowledge corresponded to a score less than the mean.

The axillary body temperature of each child was measured using an electronic thermometer and fever was classified as body temperature $\geq 37.5^{\circ} \mathrm{C}$.

\section{Malaria parasite detection and assessment}

Out of the $4 \mathrm{ml}$ of blood collected by venepuncture using a sterile $5 \mathrm{ml}$ syringe, 6 and $3 \mu \mathrm{l}$ were dispensed immediately on the same slide for the preparation of thick and thin blood films, respectively. The films were Giemsastained and examined in the laboratory following standard procedures [29]. The malaria parasite density was determined from the thick blood film by counting the number of parasites per 200 leukocytes on thick blood film and multiplying the parasite count with the participants' white blood cell count obtained from the complete blood count analysis. Malaria parasite density was categorized as low ( $<1000$ parasites/ $\mu$ l blood), moderate (1000-4999 parasites/ $\mu \mathrm{l}$ blood), high (5000-99,999 parasites/ $\mu$ l blood), and hyper parasitaemia ( $\geq 100,000$ parasites/ $\mu$ l blood) $[4]$.

\section{Determination of haematological parameters}

Briefly, the blood samples were placed on a multi mixer rotator for uniform mixing. A complete blood count was run following the manufacturer's instructions using an auto-haematology analyser (MINRAY 2800 BC) to obtain haemoglobin concentration (Hb), haematocrit (Hct), mean corpuscular volume (MCV), mean corpuscular haemoglobin concentration (MCHC), mean corpuscular haemoglobin $(\mathrm{MCH})$, and red blood cell distribution width coefficient of variation (RDW-CV). Anaemia was defined as $\mathrm{Hb}<11 \mathrm{~g} / \mathrm{dl}$ and further classified as mild $(\mathrm{Hb}$, $10.1-10.9 \mathrm{~g} / \mathrm{dl})$, moderate $(\mathrm{Hb}, 7.0-10.0 \mathrm{~g} / \mathrm{dl})$ and severe $(\mathrm{Hb}<7 \mathrm{~g} / \mathrm{dl})[30]$.

\section{Statistical analysis}

Data was entered into log books and later entered into spread sheets using Microsoft Excel. After data cleansing, analysis was performed using the Statistical Package for Social Sciences (SPSS) version 20 (IBM-SPSS, Inc, Chicago, IL, USA) and Epi-Info version 7 software. Data was summarized into means and standard deviations (SD), and percentages were used in the evaluation of the descriptive statistics. The comparison between malaria parasite, anaemia, ITN (ownership and usage), as dependent variables and demographic and clinical variables as independent variables were evaluated using the Chi-square test $\left(x^{2}\right)$. Malaria parasite counts were log transformed before analysis. The geometric mean parasite densities (GMPDs) were used to compare the intensity of infection in the study population and differences were compared using Mann-Whitney $U$ test and Kruskal-Wallis test where appropriate. The combined level of knowledge of malaria was classified according to each respondent's score. The mean knowledge score was 5. Appropriate knowledge corresponded to a score greater than or equal to 5 , while inappropriate knowledge corresponded to a score less than 5. A multilinear regression model was used to determine the relationship of each haematological parameter as dependent variable and age, gender, knowledge about malaria, malaria parasite status, ITN use, and effective use of ITN as independent variables. Significant levels were measured at 95\% confidence interval (CI) with significant differences designated at $\mathrm{P}<0.05$.

\section{Ethical considerations and administrative approval}

Ethical approval for the study was obtained from the Institutional Review Board of the Faculty of Health Sciences, University of Buea (2017/004/UB/FHS/IRB) following an administrative clearance from the South West Regional Delegation of Public Health, Cameroon. Informed consent/assent forms were read, given and explained to parents or caregivers of the children at presentation. The role of the participants was well explained and only participants who gave written and/or verbal consent or assent took part in the study. Even though participation was voluntary, parents or caregivers were free at any point to terminate the participation of the child/children in the study.

\section{Results}

\section{Characteristics of the study population}

A total of 405 children with a mean (SD) age of 6.31(3.54) years, and of both sexes; males $(48.9 \%, 198)$ and females $(51.1 \%, 207)$ residing in Batoke-Limbe participated in the study. The ITN ownership (N) was $78.8 \%$ (319) with a utilization of $50.9 \%$ (206). Most of the parents/ guardians of the children had a primary level of education $(45.9 \%$, $170)$ with a few $(5.1 \%, 19)$ having no formal education. The proportion of children who effectively used a mosquito net was $29.9 \%$ (121), with a great proportion of the nets in good condition (Table 1). The proportion of fever, MP and anaemia in the study population were $7.9 \%$ (32), $46.7 \%$ (189) and $54.6 \%$ (221), respectively as shown in Table 1.

\section{Malaria parasite prevalence and density}

Overall, prevalence of malaria parasitaemia (MP) in the study population was $46.7 \%(189 / 405)$ and majority of the children had a low $(74.6 \%, 141)$ followed by moderate $(20.0 \%, 38)$ and high parasitaemia $(5.4 \%, 10)$. As shown in Table 2, MP prevalence was similar between males (44.9\%) and females (48.3\%). A significant difference 
Table 1 Socio-demographic and clinical characteristics of the study population

\begin{tabular}{ll}
\hline Parameter & $\%(\mathbf{N})$ \\
\hline Number of participants & $100(405)$ \\
Mean age (SD) in years & $6.31(3.54)$ \\
Age groups (years) & \\
$<5$ & $37.8(153)$ \\
$5-9$ & $40.2(163)$ \\
10-14 & $22(89)$ \\
Sex & \\
Male & $48.9(198)$ \\
Female & $51.1(207)$ \\
ITN coverage (N) & $78.8(319)$ \\
Educational level of parent/caregiver & \\
No formal & $5.1(19)$ \\
Primary & $45.9(170)$ \\
Secondary & $39.7(147)$ \\
Tertiary & $9.2(34)$ \\
Mosquito bed net use & \\
Yes & $50.9(206)$ \\
No & $49.1(199)$ \\
Effective utilization of bed nets & \\
Yes & $29.9(121)$ \\
No & $70.1(284)$ \\
Integrity of mosquito bed net & \\
Good & $71.6(290)$ \\
Torn & $6.9(28)$ \\
Mevinical & $0.2(1)$ \\
Mean teaner prevale & $36.71(0.69)$ \\
\hline
\end{tabular}

$(\mathrm{P}=0.03)$ was observed with age, with the $5-9$ years age group having the highest prevalence $(54.6 \%)$. In addition, a significant difference $(\mathrm{P}=0.02)$ was observed in the parasite density with respect to age; with the $<5$ years age group having the highest geometric mean parasite density (GMPD)/ $\mu$ l of blood (537) and the least observed in the 10-14 years age group (319). Children who did not use ITNs as well as those whose ITNs were torn had a higher prevalence of MP than their respective counterparts although not statistically significant (Table 2).

\section{Prevalence and severity of anaemia}

The overall prevalence of anaemia was $54.6 \%$. The prevalence of anaemia decreased significantly $(\mathrm{P}<0.001)$ with an increase in age group. Contrarily, the youngest age group ( $<5$ years) had the highest prevalence of severe anaemia (5.2\%), than those older (5-9 and $10-14$ years) although the difference was not significant as shown in Table 3. Parasitaemic children and those who presented with fever had higher prevalence of anaemia $(70.4 \%$ and $62.5 \%$ ) than their respective negative counterparts. However, only the difference in prevalence by parasitaemia status was significant $(\mathrm{P}<0.001)$. On the severity of anaemia, the proportion of parasitaemia positive children with severe to moderate anaemia was significantly lower $\left(X^{2}=7.17, P=0.03\right)$ than their negative counterparts. Similarly, the proportion of afebrile children with moderate and mild anaemia was significantly higher $\left(x^{2}=10.65\right.$, $\mathrm{P}=0.005)$ than in the febrile children as shown in Table 3

ITN ownership, utilisation rates and malariometric indices As shown in Fig. 2, although not significant, the proportion of females with ITN (79.2\%) and females who slept under bed nets $(52.7 \%)$ were greater than the males while, with age the ownership and utilization was higher in the $<5$ years age group than counterparts. Also, ownership and utilization of ITN among anaemic and nonanaemic children was comparable.

The proportion of ineffective users was significantly higher $\left(X^{2}=26.08, \quad P<0.001\right)$ in children who were malaria parasite positive $(54.9 \%)$ than negative $(27.3 \%)$ as shown in Fig. 3.

The mean parasite density was comparable between ITN users (2.63 parasite/ $\mu$ l of blood) and non ITN users (2.67 parasite/ $\mu$ l of blood). However, the mean parasite density was lower $(t=-5.138, \mathrm{P}<0.001)$ among children who effectively used ITN (2.24 parasite/ $\mu$ l of blood) compared to those who didn't (2.74 parasite/ $\mu$ l of blood) as seen in Fig. 4.

\section{Knowledge and malaria parasite status}

The overall appropriate knowledge on malaria was $40.7 \%$. As shown in Table 4, there was a significant association $(\mathrm{P}<0.001)$ between knowledge of malaria and parasitaemia status. The proportion of parasitaemia positive cases whose parents/caregivers had appropriate knowledge on malaria (30.7\%) was significantly lower than their negative counterparts (49.5\%). The level of appropriate knowledge of malaria decreased significantly $(P=0.001)$ with the level of education of parents/caregivers of the children (tertiary: $61.8 \%$ and no formal:21.1\%) as shown in Table 4.

\section{Malaria parasite, ITN, knowledge and haematological indices}

The effect of malaria parasite on haematological indices is presented in Additional file 1 where, significantly lower Hb levels $(\mathrm{P}<0.001)$, Hct $(\mathrm{P}<0.001)$, and $\mathrm{RBC}$ counts 
Table 2 Malaria parasite prevalence and density with respect to sex, age, and ITN use

\begin{tabular}{|c|c|c|c|c|c|c|}
\hline \multirow[t]{2}{*}{ Parameter } & \multirow[t]{2}{*}{ No. examined } & \multirow[t]{2}{*}{ Prevalence (n) } & \multirow[t]{2}{*}{ P-value } & \multicolumn{2}{|c|}{ Parasite density (parasites/ $\mu \mathrm{l}$ of blood } & \multirow[t]{2}{*}{ P-value } \\
\hline & & & & GMPD/ $\mu \mathrm{l}$ & Range & \\
\hline \multicolumn{7}{|l|}{ Gender } \\
\hline Male & 198 & $44.9(89)$ & $P=0.50^{c}$ & 433 & $100-10,920$ & $0.56^{\mathrm{a}}$ \\
\hline Female & 207 & $48.3(100)$ & & 464 & $104-11,520$ & \\
\hline \multicolumn{7}{|c|}{ Age group in years } \\
\hline$<5$ & 153 & $41.2(63)$ & $P=0.03^{* c}$ & 538 & $104-11,520$ & $0.02^{* a}$ \\
\hline $5-9$ & 163 & $54.6(89)$ & & 456 & $100-10,920$ & \\
\hline $10-14$ & 89 & $41.6(37)$ & & 319 & $100-5740$ & \\
\hline \multicolumn{7}{|l|}{ ITN ownership } \\
\hline Yes & 319 & $45.5(145)$ & $P=0.346^{c}$ & 474 & $100-11,520$ & $0.65^{\mathrm{a}}$ \\
\hline No & 86 & $51.2(44)$ & & 376 & $100-10,920$ & \\
\hline \multicolumn{7}{|l|}{ ITN usage } \\
\hline Yes & 206 & $44.2(91)$ & $P=0.306^{c}$ & 431 & $107-9300$ & $0.63^{\mathrm{a}}$ \\
\hline No & 199 & $49.2(98)$ & & 468 & $100-11,520$ & \\
\hline \multicolumn{7}{|c|}{ Integrity of ITN } \\
\hline Good & 290 & $45.9(133)$ & $P=0.438^{c}$ & 483 & $100-11,520$ & $0.807^{b}$ \\
\hline Acceptable & 28 & $39.3(11)$ & & 416 & 138-1890 & \\
\hline Torn & 1 & $100(1)$ & & 170 & $170-170$ & \\
\hline
\end{tabular}

* Statistically significant at $\mathrm{P}<0.05$

${ }^{\text {a }}$ Difference in GMPD determined by Mann-Whitney

${ }^{\mathrm{b}}$ Difference in GMPD determined by Krustal-Wallis

${ }^{\mathrm{c}}$ Difference in proportions determined by Chi square

Table 3 Prevalence of anaemia and its severity as affected by age, malaria parasite and fever statuses

\begin{tabular}{|c|c|c|c|c|c|c|c|c|}
\hline \multirow[t]{2}{*}{ Variable } & \multirow[t]{2}{*}{$\mathbf{N}$} & \multirow[t]{2}{*}{ Anaemia } & \multirow{2}{*}{$\begin{array}{l}\text { Chi square } \\
\text { P-value }\end{array}$} & \multicolumn{4}{|c|}{ Anaemia severity } & \multirow{2}{*}{$\begin{array}{l}\text { Chi } \\
\text { square } \\
\text { P-value }\end{array}$} \\
\hline & & & & $\mathrm{N}$ & Severe \% (n) & Moderate \% (n) & Mild \% (n) & \\
\hline \multicolumn{9}{|l|}{ Age group } \\
\hline$<5$ & 153 & $63.4(97)$ & \multirow{3}{*}{$\begin{array}{l}16.28 \\
<0.001^{* * *}\end{array}$} & 97 & $5.2(5)$ & $55.7(54)$ & $39.2(38)$ & \multirow{3}{*}{$\begin{array}{l}4.47 \\
0.35\end{array}$} \\
\hline $5-9$ & 163 & $55.8(91)$ & & 91 & $2.2(2)$ & $56.0(51)$ & $41.8(38)$ & \\
\hline $10-14$ & 89 & $37.1(33)$ & & 33 & $0(0)$ & $45.5(15)$ & $54.5(18)$ & \\
\hline \multicolumn{9}{|c|}{ Malaria parasite status } \\
\hline Positive & 189 & $70.4(133)$ & \multirow{2}{*}{$\begin{array}{l}35.70 \\
<0.001^{* * *}\end{array}$} & 133 & $2.3(3)$ & $48.1(64)$ & $49.6(66)$ & \multirow{2}{*}{$\begin{array}{l}7.17 \\
0.03^{*}\end{array}$} \\
\hline Negative & 216 & $40.7(88)$ & & 88 & $4.5(4)$ & $63.6(56)$ & $31.8(28)$ & \\
\hline \multicolumn{9}{|c|}{ Fever status } \\
\hline Febrile & 32 & $62.5(20)$ & \multirow{2}{*}{$\begin{array}{l}0.88 \\
0.36\end{array}$} & 31 & $12.9(4)$ & $48.4(15)$ & $38.7(12)$ & \multirow{2}{*}{$\begin{array}{l}10.65 \\
0.005^{*}\end{array}$} \\
\hline Afebrile & 373 & $53.9(201)$ & & 183 & $1.6(3)$ & $56.3(103)$ & $42.1(77)$ & \\
\hline
\end{tabular}

* Statistically significant at $\mathrm{P}<0.05$

** Statistically significant at $\mathrm{P}<0.01$

*** Statistically significant at $\mathrm{P}<0.001$

$(\mathrm{P}<0.001)$ were observed in malaria parasite positive children than negative. Also, children who used ITN had significant higher mean $\mathrm{Hb}$ levels $(\mathrm{P}=0.032), \mathrm{RBC}$ count $(\mathrm{P}=0.009)$, $\mathrm{MCHC}(\mathrm{P}=0.039)$, $\mathrm{RDW}-\mathrm{CV}(\mathrm{P}=0.036)$ and PLT count $(\mathrm{P}=0.007)$ compared to those who did not use ITN as shown in Additional file 2.
Using a multilinear regression model with each haematological variable as the dependent variable, to examine the influence of age, gender, knowledge on malaria, ITN use, effective ITN use and parasitaemia status on each haematological variable; it was observed that age negatively correlated with WBC $(\mathrm{P}<0.001)$ 


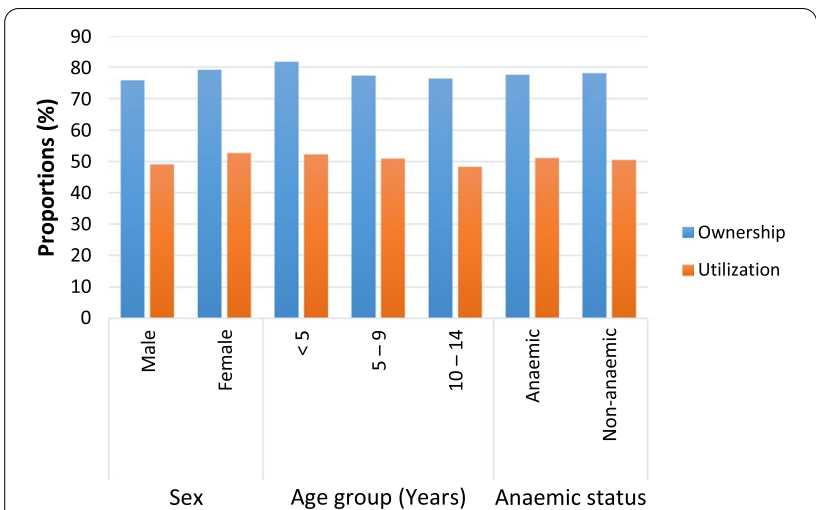

Fig. 2 Ownership and utilization of ITN with respect to sex, age and anaemic status

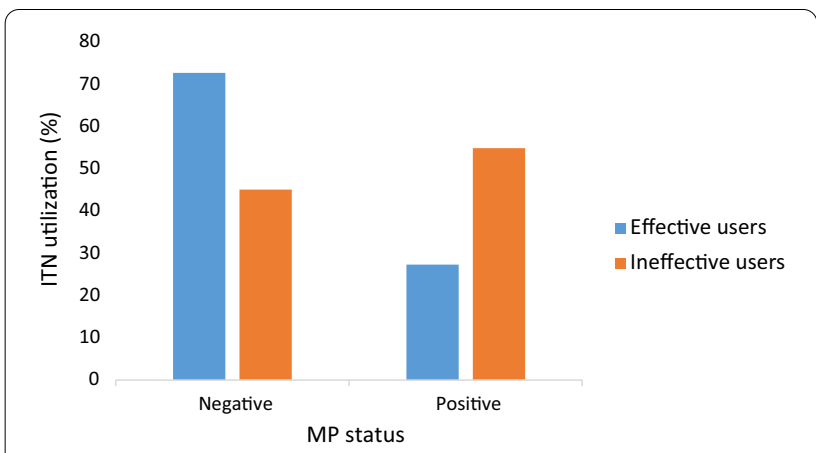

Fig. 3 Effective utilization of ITN with respect to MP status
Table 4 Effects of clinical and demographic factors on malaria knowledge

\begin{tabular}{|c|c|c|c|c|}
\hline \multirow[t]{2}{*}{ Variable } & \multirow[t]{2}{*}{$\mathbf{N}$} & \multicolumn{2}{|c|}{ Malaria knowledge \% (n) } & \multirow{2}{*}{$\begin{array}{l}X^{2} \\
P\end{array}$} \\
\hline & & Appropriate & Inappropriate & \\
\hline \multicolumn{5}{|c|}{ Asexual malaria parasite status } \\
\hline Negative & 216 & $49.5(107)$ & $50.5(109)$ & \multirow{2}{*}{$\begin{array}{l}14.834 \\
<0.001^{* * *}\end{array}$} \\
\hline Positive & 189 & $30.7(58)$ & $69.3(131)$ & \\
\hline \multicolumn{5}{|c|}{ Age group of parents/caregivers } \\
\hline$<30$ & 143 & $34(49)$ & $66(74)$ & \multirow{3}{*}{$\begin{array}{l}5.85 \\
0.05\end{array}$} \\
\hline $31-40$ & 172 & $43.2(74)$ & $56.8(98)$ & \\
\hline$>40$ & 90 & $49.0(41)$ & $51.0(46)$ & \\
\hline \multicolumn{5}{|c|}{ Educational level of parents/caregivers } \\
\hline No formal & 19 & $21.1(4)$ & $78.9(15)$ & \multirow{4}{*}{$\begin{array}{l}13.26 \\
<0.001^{* * *}\end{array}$} \\
\hline Primary & 170 & $34.7(59)$ & $65.3(111)$ & \\
\hline Secondary & 147 & $45.6(67)$ & $54.4(80)$ & \\
\hline Tertiary & 34 & $61.8(21)$ & $38.2(13)$ & \\
\hline
\end{tabular}

* Statistically significant at $\mathrm{P}<0.05$

*** Statistically significant at $\mathrm{P}<0.001$

and positively correlated with $\mathrm{Hb}(\mathrm{P}=0.013)$, MCV $(\mathrm{P}<0.001)$ and $\mathrm{MCH} \quad(\mathrm{P}<0.001)$. Malaria knowledge negatively correlated with WBC $(\mathrm{P}=0.005)$ but positively correlated with $\mathrm{Hb}$ levels $(\mathrm{P}<0.001), \mathrm{RBC}$ counts $(\mathrm{P}<0.001)$, Hct $(\mathrm{P}<0.001)$, MCV $(\mathrm{P}<0.001)$ and $\mathrm{MCH}$ $(P<0.001)$. Similarly, ITN use positively correlated with WBC counts $(P=0.005)$ but negatively correlated with Hb levels $(P=0.004)$, RBC counts $(P=0.006)$, and $\mathrm{MCH}$ $(\mathrm{P}<0.001)$. In addition, a significant negative correlation of effective ITN use with WBC $(\mathrm{P}=0.006)$ was observed. Furthermore, MP negatively correlated with $\mathrm{Hb}$ levels $(\mathrm{P}=0.004)$, RBC counts $(\mathrm{P}=0.01)$, Hct $(\mathrm{P}=0.04)$ and $\mathrm{MCHC}(\mathrm{P}=0.015)$ as shown in (Table 5).

\section{Discussion}

Insecticide-treated net use is a well-established malaria control intervention recommended in malaria endemic countries around the globe. Considerable progress with the use of interventions such as ITN and use of artemisinin-based combination therapy has been made in the past decade in reducing the burden of malaria in Africa, with Cameroon inclusive [4,9]. The objective of this study was to determine the impact of ITN ownership and utilization as well as knowledge of malaria on malariometric and haematological indices in children in Batoke, a malaria meso endemic coastal town in the Mount Cameroon area.

The overall malaria parasitaemia of $46.7 \%$ in the population confirms earlier findings of the meso-to-hyper endemicity of malaria in the Mount Cameroon area [31, 32]. The observation is similar to the $47.5 \%$ reported by Sumbele et al. [31] among children less than 15 years in

Fig. 4 Mean parasitaemia density as affected by ITN usage 
Table 5 Multiple linear regression analyses examining the influence of independent variables on each haematologic measure

\begin{tabular}{|c|c|c|c|c|c|c|}
\hline $\begin{array}{l}\text { Haematological } \\
\text { Parameter }\end{array}$ & Mean (SD) & Independent variable & $\beta$ value & $P$ value & Partial correlation & $\mathrm{R}^{2}$ \\
\hline \multirow[t]{6}{*}{$\mathrm{WBC} \times 10^{9} / \mathrm{I}$} & $7.9(3.7)$ & Age & -0.28 & $<0.001^{* * *}$ & -1.39 & 0.14 \\
\hline & & Sex & 0.03 & 0.484 & 0.25 & \\
\hline & & Knowledge & -0.13 & $0.005^{* *}$ & -1.02 & \\
\hline & & ITN use & 0.18 & $0.003^{* *}$ & 1.37 & \\
\hline & & Effective ITN use & -0.17 & $0.006^{* *}$ & -1.42 & \\
\hline & & Malaria parasite & 0.08 & 0.124 & 0.57 & \\
\hline \multirow[t]{6}{*}{$\mathrm{Hb}(\mathrm{g} / \mathrm{dl})$} & $11.0(2.0)$ & Age & 0.11 & $0.013^{*}$ & 2.95 & 0.26 \\
\hline & & Sex & 0.01 & 0.830 & 0.38 & \\
\hline & & Knowledge & 0.46 & $<0.001^{* * *}$ & 19.3 & \\
\hline & & ITN use & -0.17 & $0.004^{* *}$ & -6.80 & \\
\hline & & Effective ITN use & 0.09 & 0.143 & 3.86 & \\
\hline & & Malaria parasite & -0.15 & $0.004^{* *}$ & -2.01 & \\
\hline \multirow[t]{6}{*}{$\mathrm{RBC} \times 10^{9} / \mathrm{I}$} & $5.0(1.1)$ & Age & -0.04 & 0.358 & -0.06 & 0.14 \\
\hline & & Sex & 0.03 & 0.481 & 0.07 & \\
\hline & & Knowledge & 0.32 & $<0.001^{* *}$ & 0.67 & \\
\hline & & ITN use & -0.17 & $0.006^{* *}$ & -0.35 & \\
\hline & & Effective ITN use & 0.06 & 0.390 & 0.122 & \\
\hline & & Malaria parasite & -0.16 & $0.01^{* *}$ & -0.126 & \\
\hline \multirow[t]{6}{*}{ Hct (\%) } & $36.1(7.4)$ & Age & 0.07 & 0.133 & 0.66 & 0.22 \\
\hline & & Sex & 0.03 & 0.495 & 0.45 & \\
\hline & & Knowledge & 0.42 & $<0.001^{* *}$ & 6.33 & \\
\hline & & ITN use & -0.11 & 0.07 & -1.56 & \\
\hline & & Effective ITN use & 0.03 & 0.585 & 0.53 & \\
\hline & & Malaria parasite & -1.63 & $0.04^{*}$ & -1.14 & \\
\hline \multirow[t]{6}{*}{$M C V /(f))$} & $74.2(8.7)$ & Age & 0.16 & $0.001^{* * *}$ & 1.86 & 0.08 \\
\hline & & Sex & -0.06 & 0.220 & -1.03 & \\
\hline & & Knowledge & 0.17 & $<0.001^{* * *}$ & 3.06 & \\
\hline & & ITN use & 0.09 & 0.169 & 1.52 & \\
\hline & & Effective ITN use & -0.05 & 0.473 & -0.89 & \\
\hline & & Malaria parasite & -0.05 & 0.310 & -0.91 & \\
\hline \multirow[t]{6}{*}{$\mathrm{MCH} / \mathrm{pg}$} & $22.6(2.5)$ & Age & 0.26 & $<0.001^{* * *}$ & 0.86 & 0.13 \\
\hline & & Sex & -0.05 & 0.324 & -0.23 & \\
\hline & & Knowledge & 0.21 & $<0.001^{* * *}$ & 1.05 & \\
\hline & & ITN use & -0.05 & 0.456 & -0.23 & \\
\hline & & Effective ITN use & 0.02 & 0.780 & 0.10 & \\
\hline & & Malaria parasite & -0.01 & 0.924 & -0.02 & \\
\hline \multirow[t]{6}{*}{$\mathrm{MCHC}(\mathrm{g} / \mathrm{l})$} & $305.9(27.1)$ & Age & 0.09 & 0.063 & 3.31 & 0.04 \\
\hline & & Sex & -0.01 & 0.923 & -0.26 & \\
\hline & & Knowledge & 0.08 & 0.105 & 4.51 & \\
\hline & & ITN use & -0.16 & $0.017^{*}$ & -8.45 & \\
\hline & & Effective ITN use & 0.10 & 0.153 & 5.68 & \\
\hline & & Malaria parasite & 0.13 & $0.015^{*}$ & 6.94 & 0.11 \\
\hline \multirow[t]{6}{*}{ RDW-CV/\% } & $15.9(3.6)$ & Age & 0.23 & $0.001^{* * *}$ & 1.03 & \\
\hline & & Sex & 0.09 & $0.049^{*}$ & 0.67 & \\
\hline & & Knowledge & -0.04 & 0.403 & -0.30 & \\
\hline & & ITN use & -0.29 & $0.001^{* * *}$ & -2.05 & \\
\hline & & Effective ITN use & 0.30 & $0.001^{* * *}$ & 2.32 & \\
\hline & & Malaria parasite & 0.10 & 0.060 & 0.68 & \\
\hline
\end{tabular}


Table 5 (continued)

\begin{tabular}{|c|c|c|c|c|c|c|}
\hline $\begin{array}{l}\text { Haematological } \\
\text { Parameter }\end{array}$ & Mean (SD) & Independent variable & $\beta$ value & P value & Partial correlation & $\mathrm{R}^{2}$ \\
\hline \multirow[t]{6}{*}{$\mathrm{Plt} / \mathrm{l}$} & $328.1(141.1)$ & Age & 0.15 & $0.003^{* *}$ & 28.04 & 0.04 \\
\hline & & Sex & 0.02 & 0.765 & 4.15 & \\
\hline & & Knowledge & 0.02 & 0.733 & 4.94 & \\
\hline & & ITN use & -0.19 & $0.004^{* *}$ & -52.25 & \\
\hline & & Effective ITN use & 0.09 & 0.194 & 26.81 & \\
\hline & & Malaria parasite & 0.04 & 0.932 & 1.27 & \\
\hline
\end{tabular}

* Statistically significant at $\mathrm{P}<0.05$

** Statistically significant at $P<0.01$

*** Statistically significant at $P<0.001$

this lowland area and a $45.3 \%$ reported by Eyong et al. [32] in pupils between 4 and 16 years in other areas in the Mount Cameroon area. In addition, a similar prevalence $(45.47 \%)$ was reported among school children in the Littoral Region, another coastal area of the country [33]. Worthy of note is that, this prevalence is lower than the $60.5 \%$ obtained by Ndamukong-Nyanga et al. [34] in a lowland study in the Mount Cameroon area. On the contrary, lower prevalence of $27.7 \%$ [35], 29.6\% [15] and 32.9\% [36] among a similar age group was reported in higher altitude areas, in the Mount Cameroon area and the Northern part of the country, respectively. This reveals that malaria remains a major cause of illness during childhood and the prevalence in this part of the country is not on a speedy decline. In addition, Batoke is at a lower altitude and several studies have reported that malaria prevalence is higher in lower altitude compared to their higher altitude counterparts [24, 25].

Interestingly, higher prevalence of the malaria parasite in children of the 5-9 years' age group was consistent with the findings of Apinjoh et al. [15] within the same age group in the Mount Cameroon area. Also, higher prevalence among children aged 5-15 years compared to the under-five age group in this area has been reported by Ebai et al. [37]. Additionally, in another part of the Mount Cameroon area, Bate et al. [38] reported higher malaria prevalence among children aged 5-10 years when compared to their contemporaries. The epidemiological shift in malaria burden from the under-five age group to the 5-9 years age can be attributed to the playful and adventurous nature of children of this age group in the fields, which exposes them to the malaria vector. Another possible reason for this epidemiological shift in malaria prevalence from the less than five to the 5-9 years age group could be as a result of intensive malaria control including free LLINs distribution and ACT for less than five age group in all government health centres in Cameroon as decreed by the Head of state. Furthermore, the reduced malaria prevalence in the $<5$ age group could be associated to parental guidance, bed sleeping time of the children of this age group and reinforcement on the proper use of these ITNs compared to the 5-9 age groups whose maternal care would have reduced and are more independent and less likely to use the ITNs.

Even though malaria parasite prevalence was lowest in the $<5$ years age group, children in this group had the highest GMPD. The findings are in line with those of Achidi et al. [39]; Udoh et al. [40]; Bate et al. [38] carried out in Cameroon and Nigeria. Children under five years are more vulnerable to the disease in areas of high transmission [41] and it is often associated to the poorly developed immune system in this age group [42]. Observations from this study did not report any association between gender and Plasmodium infection, consistent with studies by Kwenti et al. [43] and Mbohou et al. [44] in other parts of the country.

The overall knowledge of malaria (i.e. mode of transmission, signs and symptoms, effects and control measures) in the study area is very low. Similar results were obtained by Birhanu et al. [45] in Ethiopia, whose study revealed that local understanding of malaria was unsatisfactory and very limited. Higher educational level was significantly associated with the knowledge of malaria. The findings are in congruence with those of Yaya et al. [46] who reported the likelihood of having accurate knowledge of malaria increased as the educational level increased. Additionally, Ndibuagu et al. [47] reported respondents with formal education had significantly better knowledge of malaria than those without formal education. Higher levels of education are generally associated with improved knowledge in relation to appropriate prevention and treatment strategies [3]. 
Consequently, this justifies the findings which revealed a higher prevalence of malaria parasite among children whose parents/caregivers were less educated. Therefore, they will put in less protective measures to reduce exposure thus preventing Plasmodium infection [48].

The prevalence of anaemia (54.6\%) in children less than 15 years underscores the high burden of anaemia among the population in this area. However, this prevalence is lower compared to the $72.7 \%$ reported by Teh et al. [35] and the $62.0 \%$ and $75.3 \%$ reported by Sumbele et al. $[4,49]$ respectively, in the Mount Cameroon area. It is also lower than the national value of $62.5 \%$ [50]. It was however higher than the $44.8 \%, 49.6 \%$ and $44.7 \%$ reported by Njunda et al. [51], Bate et al. [38] and Tientche et al. [52] respectively in different locations in the Mount Cameroon area. The higher prevalence of anaemia in the population could be attributed to the burden of malaria in the population. A recent study [53] in 16 sub-Saharan African countries including Cameroon showed that anaemia is an important indicator for monitoring malaria burden.

Children of the $<5$ years age group had a significantly higher occurrence of anaemia compared to their counterparts. The higher prevalence could be linked to the higher Plasmodium density observed in this age group. Similar findings were also reported by Sumbele et al. [49]. Udoh et al. [40] reported that, anaemia due to malaria is more severe in younger children in areas of intense transmission. Likewise, there was a negative correlation between $\mathrm{Hb}$ and malaria parasitaemia, further indicating that high parasite load causes more destruction of RBCs, consequently decreasing haemoglobin levels leading to anaemia.

The proportion of bed net possession was $78.8 \%$ among the children. The coverage rate was slightly lower than the WHO recommended $80 \%$ for acceptable protection. This ownership frequency is higher than the $63.5 \%$ obtained by Fokam et al. [5] in another part of Cameroon. Also, the ownership frequency was higher than that obtained in other countries, such as Angola $(52.0 \%)$, and may be accounted for by the fact that during the free distribution campaign in Cameroon, all households were included, unlike in Angola where the distribution exercise was targeted [54]. With respect to utilization, $50.9 \%$ of the children had at least used a net the previous night, with an effective utilisation rate of $29.9 \%$. These findings are in line with those of Fokam et al. [5] who reported that, there was a negative association between bed net ownership and utilization by households as bed net ownership was high and utilisation of these nets was low. Furthermore, Inungu et al. [55] in a study in the Democratic Republic of Congo reported lower utilization rates although ownership proportions were quite high (81.6\%). These findings are not in conformity with those of Ntonifor and Veyufambom [6], where in a study carried out in the high western plateau part of the country observed that, most of the respondents that had nets usually sleep under them.

Observations from the study demonstrated significantly lower prevalence of malaria parasitaemia in children who effectively utilized the ITNs. This finding corroborates those of Ntonifor and Veyufambom, [6]. Insecticide-treated net is a highly effective means of preventing malaria vector transmission through a physical and chemical barrier, thereby reducing associated malaria morbidity and mortality, particularly in endemic areas [8]. Since transmission takes place mainly at night and, therefore, inside the house, the effective use of LLINs offers a degree of protection against the female Anopheles mosquito thus preventing malaria transmission [56].

This study confirms that haematological changes including $\mathrm{RBC}$ and its indices, are common complications encountered in Plasmodium parasite infection in children. Although malaria parasitaemia was not significantly associated with WBCs. The mean WBC counts in malaria infected and negative groups were normal and is in line with other studies [57]. Nevertheless, normal WBC counts are not enough to clearly indicate freedom from underlying disease. A differential analysis of the individual WBC counts which was a limitation of this study could have given a more precise blood picture. However, the finding contrasts those of Kimbi et al. [58] who indicated that as malaria parasitaemia rises in blood, the amount of WBC also rises. Moreover, Kotepui et al. [59] and Sumbele et al. [60], reported a lower amount of white blood cell count with increased parasitaemia.

Children who used ITN had significant higher mean $\mathrm{Hb}$ levels, RBC count, MCHC, RDW-CV and Plt count compared to those who did not use ITNs. Based on the results of the linear regression model, it was observed that ITN use had a significant influence on WBC, $\mathrm{Hb}$, $\mathrm{RBC}, \mathrm{Hct}, \mathrm{MCHC}, \mathrm{RDW}-\mathrm{CV}$ and Plt. The significantly higher $\mathrm{Hb}, \mathrm{RBC}, \mathrm{MCHC}, \mathrm{RDW}-\mathrm{CV}$ and Plt count in ITN users than non-users, may be as a result of the protective efficacy of the ITNs that prevents the ITN users from the bite of the Anopheles vector thereby preventing them from contracting the Plasmodium infection, which has been proven in several studies $[58,61,62]$ to reduce the haematological parameters of children. This finding corroborates with results of Maina et al. [61] and Kotepui et al. [59] who reported that; red blood cell counts, haemoglobin and platelets counts were significantly lower in malaria positive children than negative children. The significantly lower RBCs in malaria 
positive children than negative children could be associated with haemolysis, cytoadherance, rosetting, clumping [63]. Furthermore, significantly lower levels of haemoglobin in malaria positive than negative children can be attributed to the digestion of haemoglobin by erythrocytic stages of the malaria parasite.

The age of the children had a significant influence on $\mathrm{MCV}, \mathrm{MCH}, \mathrm{RDW}-\mathrm{CV}$ and Plt counts. Likewise, the gender had a significant influence on the WBC counts, $\mathrm{Hb}$ and RDW-CV of the children. The results are in line with those of Onwurah et al. [64] who reported that age and gender have an effect on the haematological parameters. This study suggests that changes in haematological parameters accompanied with age and gender may depend on the population and geographical area studied [65] and, therefore, reference values validated for one country should not be assumed for application in population from other countries [66].

As a limitation, the study did not explore other personal and behavioural factors such as attitude, beliefs and perception regarding the role of ITN and health care-seeking which have been reported to influence behaviours.

\section{Conclusions}

Findings of this study revealed that malaria remains prevalent and is a major cause of morbidity in children less than 15 years of age in Batoke-Limbe, Mount Cameroon area. Despite the efforts put in place by the government of Cameroon to scale up ITN distribution so that universal coverage can be attained, coverage remains lower than the $80 \%$ recommended by the WHO. Effective utilization of ITN is low and is significantly associated with a decrease in parasite prevalence hence nation-wide campaigns to educate the population on proper use of ITN should be carried out. The overall knowledge of malaria in the study area is very low and improved malaria knowledge is associated with higher level of education hence, the higher prevalence of malaria parasite among children whose parents/ caregivers were less educated. Furthermore, ITN users had a higher $\mathrm{Hb}, \mathrm{RBC}, \mathrm{MCHC}, \mathrm{RDW}-\mathrm{CV}$ and Plt count than non-users, demonstrating a protective efficacy of the ITNs by not only preventing Plasmodium transmission but reducing morbidity as well.

\section{Abbreviations}

ITN: Insecticide-treated net; LLIN: Long-lasting insecticidal net; WBC: White blood cell; RBC counts: Red blood cell; Hb level: Haemoglobin; Hct: Haematocrit; MCV: Mean corpuscular volume; MCH: Mean corpuscular haemoglobin; MCHC: Mean corpuscular haemoglobin concentration; Plt: Platelet counts.

\section{Supplementary Information}

The online version contains supplementary material available at https://doi. org/10.1186/s12936-021-03860-6.

Additional file 1. Mean haematological indices as affected by malaria parasite status.

Additional file 2. Mean haematological indices as affected by ITNs use.

\section{Acknowledgements}

The authors appreciate the support and cooperation of the parents and guardians of the children in Batoke community, the health personnel and laboratory technicians who took part in the study.

\section{Authors' contributions}

RNT participated in data collection, laboratory analysis, analysed and interpreted the data and wrote the manuscript; IUNS conceived, designed and supervised the study, participated in data analysis and interpretation, and was a major contributor to the write-up of the manuscript; GAN participated in data collection, and laboratory analysis; DNM participated in data collection, and laboratory analysis; STO participated in data collection and laboratory analysis; EAT participated in data analysis and interpretation and contributor to the write-up of the manuscript; HKK participated in the study design, supervision and revision of the manuscript. All authors read and approved the final manuscript.

\section{Funding}

This work was supported by the special fund for research and modernisation given to the authors by the Government of Cameroon.

\section{Availability of data and materials}

All datasets on which the conclusions of the research rely are presented in this paper. However, data is available from the corresponding author on reasonable request.

\section{Declarations}

\section{Ethics approval and consent to participate}

The study was approved by the Institutional Review Board hosted by the Faculty of Health Sciences, University of Buea (2017/004/UB/SG/RB/FHS) following administrative clearance from the South West Regional Delegation of Public Health, Cameroon. Informed consent/assent forms and information sheets were given or read and explained to parents, caregivers of the children at presentation. The purpose and benefits of the study as well as the amount of blood to be collected from each child was clearly stated on the consent/ assent forms. Participation was strictly voluntary, and parents or caregivers were free at any point in time to stop the participation of the child/children in the study. All cases of malaria were referred to the nearest health centre.

\section{Consent for publication}

Not applicable.

\section{Competing interests}

The authors declare that they have no competing interests.

\section{Author details}

'Department of Zoology and Animal Physiology, University of Buea, Buea, Cameroon. ${ }^{2}$ Department of Social Economy and Family Management, Higher Technical Teachers'Training College, University of Buea, Kumba, Cameroon. ${ }^{3}$ Clinical Diagnostic Laboratory, University of Buea, Buea, Cameroon. ${ }^{4}$ Department of Microbiology, Kenyatta University, Nairobi, Kenya. ${ }^{5}$ Department of Medical Laboratory Sciences, The University of Bamenda, Bambili, Cameroon. ${ }^{6}$ Department of Microbiology and Immunology, Cornell College of Veterinary Medicine, Ithaca, NY, USA.

Received: 31 August 2020 Accepted: 20 July 2021

Published online: 29 July 2021 


\section{References}

1. WHO. Malaria Vaccine Implementation Programme (Mvip): proposed framework for policy decision on Rts, S/As01 malaria vaccine. Geneva: World Health Organization; 2019.

2. WHO. World malaria report 2018. Geneva: World Health Organization; 2018. https://www.who.int/malaria/publications/world_malaria_report_ 2018.

3. Kimbi HK, Nkesa SB, Ndamukong-Nyanga JL, Sumbele I, Atashali J, Atanga MB. Knowledge and perceptions towards malaria prevention among vulnerable groups in the Buea Health District, Cameroon. BMC Public Health. 2014;14:883.

4. Sumbele IU, Ning TR, Bopda OS, Nkuo-Akenji T. Variation in malariometric and red cell indices in children in the Mount Cameroon area following enhanced malaria control measures: evidence from a repeated crosssectional study. Malar J. 2014;13:334

5. Fokam EB, Kindzeka GF, Ngimuh L, Dzi KT, Wanji S. Determination of the predictive factors of long-lasting insecticide-treated net ownership and utilisation in the Bamenda Health District of Cameroon. BMC Public Health. 2017;17:263.

6. Ntonifor $\mathrm{NH}$, Veyufambom S. Assessing the effective use of mosquito nets in the prevention of malaria in some parts of Mezam division, Northwest Region Cameroon. Malar J. 2016;15:390.

7. Hawley WA, Phillips-Howard PA, ter Kuile FO, Terlouw DJ, Vulule JM, et al. Community-wide effects of permethrin-treated bed nets on child mortality and malaria morbidity in western Kenya. Am J Trop Med Hyg. 2003:68:121-7.

8. Lengeler C. Insecticide-treated bed nets and curtains for preventing malaria. Cochrane Database Syst Rev. 2004;2:CD000363.

9. Bhatt S, Weiss D, Cameron E, Bisanzio D, Mappin B, Dalrymple U, et al. The effect of malaria control on Plasmodium falciparum in Africa between 2000 and 2015. Nature. 2015:526:207-11.

10. Mukonka VM, Chanda E, Haque U, Kamuliwo M, Mushinge G, Chileshe J, et al. High burden of malaria following scale-up of control interventions in Nchelenge District, Luapula Province, Zambia. Malar J. 2014;13:153.

11. Louis VR, Schoeps A, Tiendrebéogo J, Beiersmann C, Yé M, Damiba MR, Lu GY, et al. An insecticide-treated bed-net campaign and childhood malaria in Burkina Faso. Bull World Health Organ. 2015;93:750-8.

12. Zgambo M, Mbakaya BC, Kalembo FW. Prevalence and factors associated with malaria parasitaemia in children under the age of five years in Malawi: a comparison study of the 2012 and 2014 Malaria Indicator Surveys (MISs). PLOS ONE. 2017;12:e0175537.

13. $\mathrm{MOH}, \mathrm{ONSP}$, African Health Observatory, WHO: Health Analytical Profile 2016 Cameroon. In: Yaoundé Observatoire National de la Sante Publique; 2017.

14. Njumkeng C, Apinjoh TO, Anchang-Kimbi JK, Amin ET, Tanue EA, Njua-Yafi C, et al. Coverage and usage of insecticide treated nets (ITNs) within households: associated factors and effect on the prevalence of malaria parasitemia in the Mount Cameroon area. BMC Public Health. 2019:19:1216.

15. Apinjoh TO, Anchang-Kimbi JK, Mugri RN, Tangoh DA, Nyingchu RV, Chi $\mathrm{HF}$, et al. The Effect of insecticide treated nets (ITNs) on Plasmodium falciparum infection in rural and semiurban communities in the South West Region of Cameroon. PLoS ONE. 2015;10:e0116300.

16. Boussougou-Sambe ST, Awono-Ambene P, Tasse GC, Etang J, Binyang JA, Nouage LD, et al. Physical integrity and residual bio-efficacy of used LLINs in three cities of the South-West region of Cameroon 4 years after the first national mass-distribution campaign. Malar J. 2017;16:31.

17. Shah MP, Steinhardt LC, Mwandama D, Mzilahowa T, Gimnig JE, Bauleni $A$, et al. The effectiveness of older insecticide-treated bed nets (ITNs) to prevent malaria infection in an area of moderate pyrethroid resistance: results from a cohort study in Malawi. Malar J. 2020;19:24

18. Bradley J, Ogouyèmi-Hounto A, Cornélie S, Fassinou J, de Tove YSS, Adéothy AA, et al. Insecticide-treated nets provide protection against malaria to children in an area of insecticide resistance in Southern Benin. Malar J. 2017;16:225.

19. Tokponnon FT, Sissinto Y, Ogouyémi AH, Adéothy AA, Adechoubou A Houansou T, et al. Implications of insecticide resistance for malaria vector control with long-lasting insecticidal nets: evidence from health facility data from Benin. Malar J. 2019;18:37

20. Kleinschmidt I, Bradley J, Knox TB, Mnzava AP, Kafy HT, Mbogo C, et al. Implications of insecticide resistance for malaria vector control with long-lasting insecticidal nets: a WHO-coordinated, prospective, international, observational cohort study. Lancet Infect Dis. 2018;18:640-9.

21. Bigoga JD, Nanfack FM, Awono-Ambene PH, Patchoké S, Atangana J, Otia VS, et al. Seasonal prevalence of malaria vectors and entomological inoculation rates in the rubber cultivated area of Niete, South Region of Cameroon. Parasit Vectors. 2012;5:197

22. Adera TD. Beliefs and traditional treatment of malaria in Kishe settlement area, southwest Ethiopia. Ethiop Med J. 2003;41:25

23. Tyagi P, Roy A, Malhotra M. Knowledge, awareness and practices towards malaria in communities of rural, semi-rural and bordering areas of east Delhi (India). J Vector Borne Dis. 2005;42:30-5.

24. Teh RN, Sumbele IUN, Meduke DN, Ojong ST, Kimbi HK. Malaria parasitaemia, anaemia and malnutrition in children less than 15 years residing in different altitudes along the slope of Mount Cameroon: prevalence, intensity and risk factors. Malar J. 2018;17:336.

25. Kimbi HK, Sumbele I, Nweboh M, Anchang-Kimbi JK, Lum E, Nana Y, et al. Malaria and haematologic parameters of pupils at different altitudes along the slope of Mount Cameroon: a cross-sectional study. Malar J. 2013;12:193.

26. Manly BF. The design and analysis of research studies. Cambridge: Cambridge University Press; 1992.

27. WHO. Report of the fifteenth WHOPES working group meeting. Geneva: World Health Organization; 2012.

28. Kimbi HK, Nkesa SB, Ndamukong-Nyanga JL, Sumbele IU, Atashili J, Atanga MB. Knowledge and perceptions towards malaria prevention among vulnerable groups in the Buea Health District, Cameroon. BMC Public Health. 2014;14:883.

29. WHO. Basic malaria microscopy. Part 1 learner's guide. 2nd ed. Geneva: World Health Organization; 2010.

30. Cheesbrough M. District laboratory practice in tropical countries: Part.1\&.2. Cambridge: Cambridge University Press; 2009.

31. Sumbele IUN, Sama SO, Kimbi HK, Taiwe GS. Malaria, moderate to severe anaemia, and malarial anaemia in children at presentation to hospital in the Mount Cameroon area: a cross-sectional study. Anemia. 2016;2016:5725634.

32. Eyong EEJ, Kengne-Ouafo AJ, Chounna PW, Datchoua-Poutcheu FR, Wanj S. Altitudinal variation in the parasitological and entomological indices of malaria around Mount Cameroon, South West Region of Cameroon. J Parasitol Vector Biol. 2016;8:74-85

33. Lehman LG, Foko LPK, Tonga C, Nyabeyeu H, Eboumbou EC, Nono LK, et al. Epidemiology of malaria using LED fluorescence microscopy among schoolchildren in Douala, Cameroon. Int J Trop Dis Health. 2018:29:1-13.

34. Ndamukong-Nyanga JL, Kimbi HK, Sumbele IUN, Nana Y, Bertek SC, Ndamukong $\mathrm{KJ}$, et al. A cross-sectional study on the influence of altitude and urbanisation on co-infection of malaria and soil-transmitted helminths in Fako Division, South West Cameroon. Int J Trop Dis Health. 2015;8:150-64

35. Teh RN, Sumbele IUN, Nkeudem GA, Meduke DN, Ojong ST, Kimbi HK. Concurrence of CareStart ${ }^{\text {TM }}$ Malaria HRP2 RDT with microscopy in population screening for Plasmodium falciparum infection in the Mount Cameroon area: predictors for RDT positivity. Trop Med Health. 2019;47:17.

36. Sakwe N, Bigoga J, Ngondi J, Njeambosay B, Esemu L, Kouambeng C, et al. Relationship between malaria, anaemia, nutritional and socioeconomic status amongst under-ten children, in the North Region of Cameroon: a cross-sectional assessment. PLoS ONE. 2019;14:e0218442.

37. Ebai CB, Kimbi HK, Sumbele I, Yunga JE, Lehman LG. Epidemiology of Plasmodium falciparum malaria in the Ikata-Likoko area of Mount Cameroon: a cross sectional study. Int J Trop Dis Health. 2016;16:1-12.

38. Bate A, Kimbi HK, Lum E, Lehman LG, Onyoh EF, Ndip LM, et al. Malaria infection and anaemia in HIV-infected children in Mutengene, Southwest Cameroon: a cross sectional study. BMC infect Dis. 2016;16:523.

39. Achidi EA, Apinjoh TO, Anchang-Kimbi JK, Mugri RN, Ngwai AN, Yafi CN. Severe and uncomplicated falciparum malaria in children from three regions and three ethnic groups in Cameroon: prospective study. Malar J. 2012;11:215.

40. Udoh E, Oyo-Ita A, Eyong K, Oringanje C, Oduwole O, Okebe J, et al. Malariometric indices among Nigerian children in rural setting. Malar Res Treat. 2013;2013:716805.

41. Kimbi H, Keka F, Nyabeyeu H, Ajeagah H, Tonga C, Lum E, et al. An update of asymptomatic falciparum malaria in school children in Muea, Southwest Cameroon. J Bacteriol Parasitol. 2012;3:8. 
42. Maziarz M, Kinyera T, Otim I, Kagwa P, Nabalende H, Legason ID, et al. Age and geographic patterns of Plasmodium falciparum malaria infection in a representative sample of children living in Burkitt lymphoma-endemic areas of northern Uganda. Malar J. 2017;16:124.

43. Kwenti TE, Kwenti TDB, Latz A, Njunda LA, Nkuo-Akenji T. Epidemiological and clinical profile of paediatric malaria: a cross sectional study performed on febrile children in five epidemiological strata of malaria in Cameroon. BMC Infect Dis. 2017;17:499.

44. Mbohou CN, Foko LPK, Nyabeyeu HN, Tonga C, Nono LK, Kangam $L$, et al. Malaria screening at the workplace in Cameroon. PLOS ONE. 2019;14:e0225219.

45. Birhanu Z, Yihdego YY-e, Yewhalaw D. Caretakers' understanding of malaria, use of insecticide treated net and care seeking-behavior for febrile illness of their children in Ethiopia. BMC Infect Dis. 2017;17:629.

46. Yaya S, Bishwajit G, Ekholuenetale M, Shah V, Kadio B, Udenigwe O. Knowledge of prevention, cause, symptom and practices of malaria among women in Burkina Faso. PLoS ONE. 2017;12:e0180508.

47. Ndibuagu EO, Omotowo B, Okafor I. Effects of formal education on malaria knowledge among residents of a rural community in Enugu state, southeast Nigeria. Med Res Chronicles. 2017;4:142-50.

48. Nyarko SH, Cobblah A. Sociodemographic detergoominants of malaria among under-five children in Ghana. Malar Res Treat. 2014;2014:304361.

49. Sumbele IUN, Nkain AJ, Ning TR, Anchang-Kimbi JK, Kimbi HK. Influence of malaria, soil-transmitted helminths and malnutrition on haemoglobin level among school-aged children in Muyuka, Southwest Cameroon: a cross-sectional study on outcomes. PLOS ONE. 2020;15:e0230882.

50. WHO. World malaria report. Geneva: World Health Organization; 2015.

51. Njunda AL, Ngouadjeu DT, Nsagha D, Nyanjoh EM, Kwenti T, Assob NJ. Haematological profile of children with malaria in Kumba Health District, South West Region Cameroon. Afr J Integr Health. 2016;6:23-9.

52. Tientche B, Anong DN, Asaah S, Fru-Cho J, Nkuo-Akenji T. Asymptomatic malaria parasitaemia in school children of Ekondo Titi sub-division, Cameroon. Int Res J Public Environ Health. 2016;3:182-90.

53. Papaioannou I, Utzinger J, Vounatsou P. Malaria-anemia comorbidity prevalence as a measure of malaria-related deaths in sub-Saharan Africa. Sci Rep. 2019;9:11323.

54. Njau JD, Stephenson R, Menon M, Kachur SP, McFarland DA. Exploring the impact of targeted distribution of free bed nets on households bed net ownership, socio-economic disparities and childhood malaria infection rates: analysis of national malaria survey data from three sub-Saharan Africa countries. Malar J. 2013;12:245.

55. Inungu JN, Ankiba N, Minelli M, Mumford V, Bolekela D, Mukoso B, et al. Use of insecticide-treated mosquito net among pregnant women and guardians of children under five in the Democratic Republic of the Congo. Malar Res Treat. 2017;2017:5923696.

56. Yang G-G, Kim D, Pham A, Paul CJ. A Meta-regression analysis of the effectiveness of mosquito nets for malaria control: the value of long-lasting insecticide nets. Inter J Environ Res Public Health. 2018;15:546.

57. Bhawna S, Bharti A, Yogesh K, Reena A. Parasitemia and hematological alterations in malaria: a study from the highly affected zones. Iran J Pathol. 2013;8:1-8.

58. Kimbi HK, Sumbele IU, Nweboh M, Anchang-Kimbi JK, Lum E, Nana Y, Ndip LM, et al. Malaria and haematologic parameters of pupils at different altitudes along the slope of Mount Cameroon: a cross-sectional study. Malar J. 2013;12:193.

59. Kotepui M, Phunphuech B, Phiwklam N, Chupeerach C, Duangmano S. Effect of malarial infection on haematological parameters in population near Thailand-Myanmar border. Malar J. 2014;13:218.

60. Sumbele IUN, Bopda OSM, Kimbi HK, Ning TR, Nkuo-Akenji T. Nutritional status of children in a malaria meso endemic area: cross sectional study on prevalence, intensity, predictors, influence on malaria parasitaemia and anaemia severity. BMC Public Health. 2015;15:1099.

61. Maina RN, Walsh D, Gaddy C, Hongo G, Waitumbi J, Otieno L, et al. Impact of Plasmodium falciparum infection on haematological parameters in children living in Western Kenya. Malar J. 2010;9:S4.

62. Imoru M, Shehu UA, Ihesiulor UG, Kwaru AH. Haematological changes in malaria-infected children in North-West Nigeria. Turk J Med Sci. 2013;43:838-42.

63. Rowe JA, Claessens A, Corrigan RA, Arman M. Adhesion of Plasmodium falciparum-infected erythrocytes to human cells: molecular mechanisms and therapeutic implications. Expert Rev Mol Med. 2009;11:e16.

64. Onwurah O, Onyenekwe C, Ifeanyichukwu M, Ezeugwunne I, Odiegwu C, Igweze Z. Haematological values for children, adults and geriatrics in Nnewi and environs, Anambra State, Nigeria. J Hematol Thromb Dis. 2018;6:23-6.

65. Mandala WL, Ananworanich J, Apornpong T, Kerr SJ, MacLennan JM, Hanson C, et al. Control lymphocyte subsets: can one country's values serve for another's. J Allergy Clin Immunol. 2014;134:759-61.e758.

66. Menard D, Mandeng MJ, Tothy MB, Kelembho EK, Gresenguet G, Talarmin A. Immunohematological reference ranges for adults from the Central African Republic. Clin Diagn Lab Immunol. 2003;10:443-5.

\section{Publisher's Note}

Springer Nature remains neutral with regard to jurisdictional claims in published maps and institutional affiliations.
Ready to submit your research? Choose BMC and benefit from:

- fast, convenient online submission

- thorough peer review by experienced researchers in your field

- rapid publication on acceptance

- support for research data, including large and complex data types

- gold Open Access which fosters wider collaboration and increased citations

- maximum visibility for your research: over $100 \mathrm{M}$ website views per year

At BMC, research is always in progress.

Learn more biomedcentral.com/submissions 